\title{
Breastfeeding During Early Infancy is Associated with a Lower Incidence of Febrile Illnesses
}

\author{
Daniel H. Libraty ${ }^{*}$, , Rosario Z. Capeding ${ }^{2,3}$, AnaMae Obcena ${ }^{2}$, Job D. Brion ${ }^{4}$ and Veronica Tallo ${ }^{5}$ \\ ${ }^{I}$ Division of Infectious Disease and Immunology, Department of Medicine, University of Massachusetts Medical School, \\ Worcester, MA, USA \\ ${ }^{2}$ Department of Medicine, Research Institute for Tropical Medicine, Manila, Philippines \\ ${ }^{3}$ Department of Microbiology, Research Institute for Tropical Medicine, Manila, Philippines \\ ${ }^{4}$ San Pablo City Health Office, San Pablo, Philippines \\ ${ }^{5}$ Department of Epidemiology, Research Institute for Tropical Medicine, Manila, Philippines
}

\begin{abstract}
Human breast milk is known to contain immunoprotective, antimicrobial, and anti-inflammatory agents. In a prospective clinical study of dengue virus infections during infancy, we examined the correlation between breastfeeding and the development of febrile illnesses in an infant population. We found that breastfeeding status and the frequency of breastfeeding during early infancy was associated with a lower incidence of febrile illnesses.
\end{abstract}

Keywords: Breastfeeding, bottle-feeding, infant, fever.

\section{INTRODUCTION}

Human breast milk is known to contain immunoprotective, antimicrobial, and anti-inflammatory agents $[1$, 2]. We therefore examined the correlation between breastfeeding and the development of febrile illnesses during early infancy in San Pablo, Laguna, Philippines. We found that breastfeeding status and the frequency of breastfeeding during early infancy was associated with a lower incidence of febrile illnesses.

\section{METHODS}

Infant Clinical Study. The infant clinical study was approved by the institutional review boards of the Research Institute for Tropical Medicine, Philippines, and the University of Massachusetts Medical School. Mothers and their healthy infants were recruited and enrolled after providing written informed consent. Study enrollment began in October 2006 in San Pablo, Philippines. Healthy infants and their mothers were enrolled when the infant was between 6-18 weeks old. The occurrence of infant febrile illnesses between birth and the first study visit was reported by the mother at the first study visit. Additional details about the study protocol have been previously reported [3].

Statistical Analysis. The SPSS software package (version 20.0) was used for statistical analyses. Ages are shown as median [95\% confidence interval]. $\mathrm{P}<0.05$ was considered significant.

*Address correspondence to this author at the Rm S6-862, Division of ID, UMMS, 55 Lake Ave N, Worcester, MA 01655, USA; Tel: 508-856-4182; Fax: 508-856-4890; E-mail: daniel.libraty@umassmed.edu

\section{RESULTS AND DISCUSSION}

Clinical study. As part of a prospective clinical study of dengue virus infections in infants, we collected information from infants' mothers on breastfeeding and the occurrence of infant febrile illnesses between birth and the first study visit (infant ages 2.1 [2.1-2.2] mos). There were $n=107$ infants with 1.0 [1.0-1.0] febrile illnesses/infant (median [95\% CI]) during this time period.

Breastfeeding during early infancy is associated with a lower incidence of febrile illnesses. Breastfeeding during early infancy (exclusive or supplemental) was associated with a lower incidence of febrile illnesses between birth and the first study visit compared to bottle-feeding (Table 1). Among breastfed infants at the first study visit $(n=7,362)$, the odds ratio for developing a febrile illness between birth and the first study visit was 0.57 [0.34-0.94] (odds ratio [95\% CI]) for every increase in breastfeeding frequency of $3 \mathrm{x} / 24 \mathrm{~h}$ (binary logistic model, $\mathrm{p}=0.03$ ). The association between breastfeeding during early infancy and a lower incidence of febrile illnesses cannot establish causation. However, the dose-response effect suggests that breastfeeding contributes to protection from febrile illnesses during early infancy; an effect that has been seen in some previous studies $[4,5]$. Some limitations of our study include the small number of febrile illnesses, potential recall bias, and the potential for confounding variables.

\section{CONFLICT OF INTEREST}

The authors confirm that this article content has no conflict of interest.

\section{ACKNOWLEDGEMENTS}

This work was supported by National Institutes of Health grant NIH/NIAID R01 AI091820. 
Table 1. Breastfeeding During Early Infancy is Associated with a Lower Incidence of Febrile Illnesses Between Birth and the First Study Visit (Infant Ages 2.1 [2.1-2.2] Mos, Median [95\% CI])

\begin{tabular}{|c|c|c|c|}
\hline & No Febrile Illnesses & Febrile Illnesses & Total \\
\hline \hline Bottle-fed (exclusive) & $N=1,689$ & $\begin{array}{c}N=31 \\
(1.8 \%)\end{array}$ & $\begin{array}{c}N=1,720 \\
(100 \%)\end{array}$ \\
\hline Breastfed (exclusive or supplemental) & $N=7,286)$ & $N=76$ \\
$(1.0 \%)$ & $(99.0 \%)$ & $(100 \%)$ \\
\hline
\end{tabular}

${ }^{\mathrm{a}} \mathrm{p}=0.01$, Fisher's exact test.

\section{REFERENCES}

[1] Goldman AS. The immune system in human milk and the developing infant. Breastfeed Med 2007; 2(4): 195-204.

[2] Hanson LA. Session 1: Feeding and infant development breastfeeding and immune function. Proc Nutr Soc 2007; 66(3): 384-96.

[3] Libraty DH, Acosta LP, Tallo V, et al. A prospective nested casecontrol study of Dengue in infants: rethinking and refining the antibody-dependent enhancement dengue hemorrhagic fever model. PLoS Med 2009; 6(10): e1000171.

[4] Launer LJ, Habicht JP, Kardjati S. Breast feeding protects infants in Indonesia against illness and weight loss due to illness. Am J Epidemiol 1990; 131(2): 322-31.

[5] Palti H, Mansbach I, Pridan H, Adler B, Palti Z. Episodes of illness in breast-fed and bottle-fed infants in Jerusalem. Isr J Med Sci $1984 ; 20(5): 395-9$.

Received: April 1, 2013

Revised: June 12, 2013

Accepted: June 15, 2013

(C) Libraty et al.; Licensee Bentham Open.

This is an open access article licensed under the terms of the Creative Commons Attribution Non-Commercial License (http://creativecommons.org/licenses/bync/3.0/) which permits unrestricted, non-commercial use, distribution and reproduction in any medium, provided the work is properly cited. 